\title{
INSIGHTS
}

\section{Family reflections: HIE and us}

Chloë Winter ${ }^{1 凶}$

(c) The Author(s), under exclusive licence to the International Pediatric Research Foundation, Inc 2021

Pediatric Research (2022) 91:705-706; https://doi.org/10.1038/s41390-021-01783-1

Our son was born at $40+4$ weeks via emergency caesarean in September 2019 after a very long and drawn out labour. We found out later that Rupert needed to be resuscitated for $6 \mathrm{~min}$ and had an APGAR score of 1 due to his heart rate being under 100. He was diagnosed as having meconium aspiration syndrome and severe/ moderate hypoxic-ischaemic encephalopathy (HIE). We were told that Rupert may not survive and if he did he would be disabled. He was transferred to the nearest available neonatal intensive care unit (NICU) and received therapeutic cooling for $72 \mathrm{~h}$. He was very stubborn and wouldn't allow the medications he was given to sedate him; however, his treatment went well and the consultants and NICU team were very pleased with him. He was taken off the ventilator and "rewarmed". His magnetic resonance imaging came back showing no concerns and we were transferred back to our local hospital. Other issues included his infection markers being raised and needing antibiotics. Rupert's heel prick test also came back showing he is a carrier of cystic fibrosis; however, there has been no follow-up from this at present.

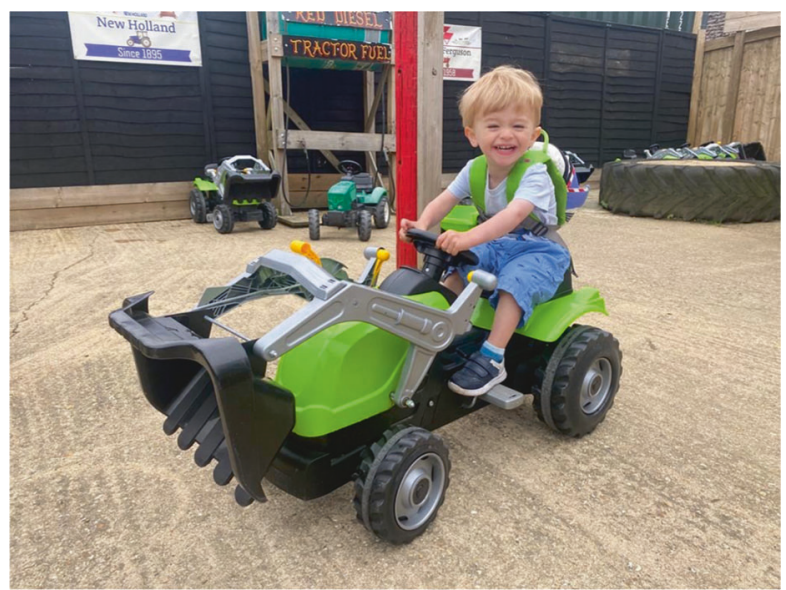

Rupert receives support from a consultant in our home town every 3-6 months, although this has been greatly affected by the Covid pandemic and he hasn't seen his consultant in person since February of 2020. He also has contact with a consultant in the neonatal hospital where he received his life-saving treatment. These appointments consist of discussing Rupert's overall health, his development and any concerns. At some of the appointments, we have also been joined by a physiotherapist to assess if Rupert showed any signs of cerebral palsy. Other than this, he receives no other treatment relating to his HIE. He does see a dietitian due to a low centile; he also has dairy and soya allergies, and all information related to this is shared with his consultants.

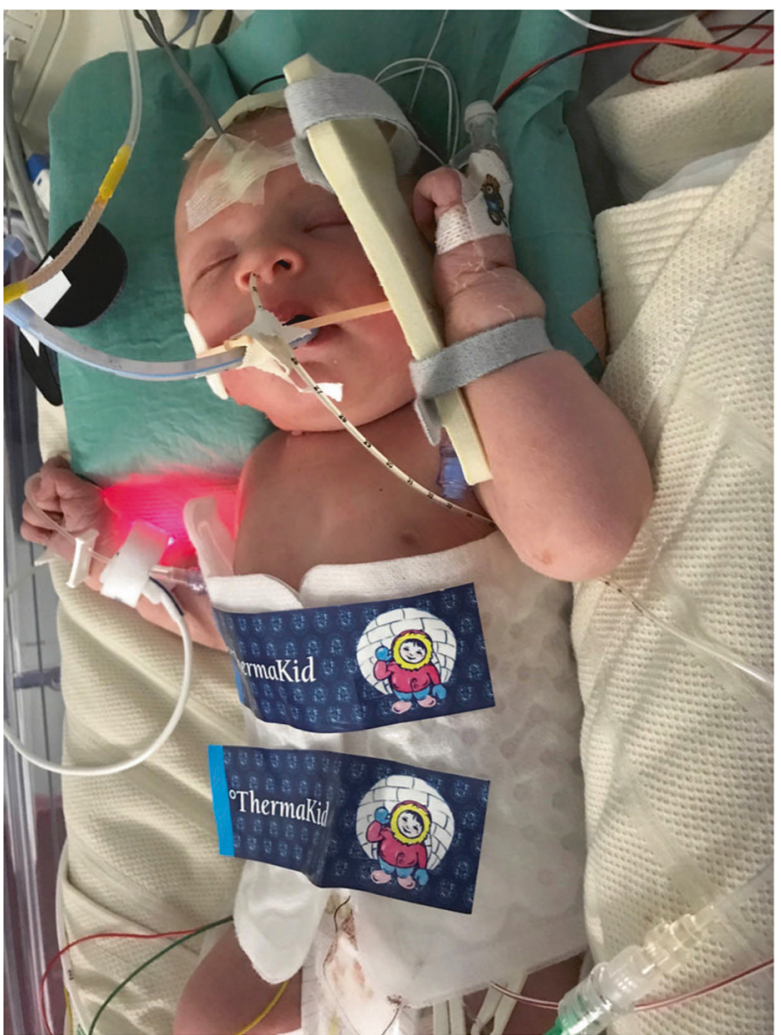

Through this journey, we have found that there is a great deal of unknown from being told by consultants that they can't "guarantee any child will walk" to "it's likely he will have lower intelligence than his peers". Rupert has shown no indication of his encephalopathy, which we are very thankful for given the shocking news delivered to us when he was born. One of the most difficult things for us as a family is that we don't know what the future holds for Rupert and the experts can only give us the worst-case scenario. As a family, we feel that the research into babies born with HIE who show no sign of their diagnosis after cooling is limited particularly after 2 years of age. Children who

${ }^{1}$ Somerset, England. ${ }^{\circledR}$ email: info@pedres.org

Received: 26 August 2021 Accepted: 26 August 2021

Published online: 19 October 2021 
meet all their developmental milestones appropriately are discharged from services, does the research stop there? It would be good to see research into how these children develop into adolescence and beyond. I believe a study into this would be helpful for those who have been told to expect the worst and left to wait for the ball to drop. The research would be simple to complete and involve tracing when those with HIE at birth access services that may be related to encephalopathy. With particular areas in mobility such as physiotherapy and any referrals to children's special educational needs or mental health services.

With that being said, any research into this area is much appreciated; as a family, we are immeasurably thankful to those who have and continue to research neonatal encephalopathy. I am a district nurse and so have some understanding of the complexities of research in healthcare, we are grateful for the work researchers have put into improving neonatal outcomes. Our son has gone from a poorly baby who doctors expected not to survive the ambulance journey from one hospital to another to a 2-year-old who is able to walk, run, show empathy, talk in sentences and most importantly is very happy. We look forward to hearing about any further research into neonatal encephalopathy and improvements in outcomes for the babies and families affected.

\section{COMPETING INTERESTS}

The authors declare no competing interests.

\section{ADDITIONAL INFORMATION}

Correspondence and requests for materials should be addressed to Chloë Winter.

Reprints and permission information is available at http://www.nature.com/ reprints

Publisher's note Springer Nature remains neutral with regard to jurisdictional claims in published maps and institutional affiliations. 